\title{
INFORMATION SYSTEMS DEVELOPMENT CONTRACTS: AN EXPLORATORY STUDY OF AUSTRALIAN LEGAL PRACTITIONERS' AND INFORMATION SYSTEMS PROFESSIONALS' PERCEPTIONS
}

\author{
Phil Joyce \\ School of Information Technology \\ Swinburne University \\ Melbourne, Victoria, Australia \\ Email: philj@it.swin.edu.au \\ Ross Smith \\ Faculty of Business and Law \\ Deakin University \\ Geelong, Victoria, Australia \\ Email: smithr@deakin.edu.au \\ Kathryn Hodges \\ Telstra Pty Ltd \\ Victoria, Australia \\ Email: Kathryn.Hodges@team.telstra.com.au
}

\begin{abstract}
IS professionals are primarily concerned with the development of a project to meet the goals of a client. Unfortunately, IS professional do not always pay close attention to the contract or to its management and are often unaware of the legal implications of the contracts to which they are assenting. Legal advice can be sought during pre-contractual processes to help ensure that the contract meets the expectations of all the parties. If the project does not meet stakeholder's expectations, thus causing a contract to come into dispute, lawyers may be called in to review the contract and to seek a settlement. This paper reports an exploratory study of the differences in perceptions of IS development contracts that exist between IS professionals and legal practitioners.
\end{abstract}

Keywords: IS Contracts, IS Professionals

\section{INTRODUCTION}

Ed Yourdon, respected commentator on Information Systems (IS) and Information Technology (IT) issues, has recently observed that "lawyers and courtrooms are probably the last thing that your average IT manager would think about during a typical systems development project" (Yourdon 2000).

The IS professional's primary focus is the development of products that meet a client's needs. In order to achieve this the IS professional goes through a process which includes the definition of requirements, the use of design principles and implementation guidelines to build the product and a review of the final product against the requirements. A step in this process for the IS professional is the preparation and development of the contract. IS professionals often view the contract as part of the normal processes that have to be gone through when developing a product. Often, however, the IS manager is unaware of the legal consequences of assenting to a contract.

In contrast, the legal practitioner sees contract development as a crucial step in building relationships. Legal practitioners focus on reducing risks in the contract, including ensuring the clarity of requirements' specifications and negotiating aspects of liability. Unfortunately, the legal profession is often brought in to review the contract only when there exists a significant difference in opinion of the product to be provided. Resolution of the disputation will require intervention by legal professionals to provide a remedy for the situation.

When examining an IS development contract in dispute a judge will take into account a number of factors. First, are there precedents that have been set in previous cases? Second, is there contract law that applies to the IS development contract? Within contract law both express terms and implied terms will be examined. Against the express and implied terms of the IS development contract a judge will need to consider the professional standards that should have been met by an IS professional and the qualifications that a professional is expected to hold. Software development practices will also be examined. If either the express or implied terms have been breached then damages could be awarded.

In summary then, clearly at the heart of Yourdon's observation is a generalisation, but nevertheless it is a concern that often the perceptions that IS/IT professionals hold of the IS development contract may be different from those of legal professionals.

In response, in this paper we address the question: Are there differences in the perceptions held by legal practitioners and IS professionals of IS development contracts? Specifically, in sections 2 and 3 we explore the extant literature, which provides the context for a subsequent semi-structured interview program. In 
section 2 we review relevant literature related to codes of ethics and professional standards, software development process quality standards, and the process of developing an IS development contract, its structure and issues surrounding contract management. In section 3 we briefly highlight some of the relevant aspects of extant Australian contract law. In sections 4 and 5 we then report an exploratory program of semi-structured interviews with a small cohort of select practitioners, probing their perceptions of the process of developing, and the content of, IS development contracts. Finally, in section 6, some brief final comments are included, addressing the scope of research to date and the way forward for research of this type.

\section{IS PROFESSIONALS AND IS CONTRACTS}

IS professionals are the people who enter into IS development contracts, usually to provide a piece of software for a client. In developing this software it is expected that they follow professional standards, both in regard to their ethical conduct and professional behaviour, as well as appropriate software implementation standards.

\section{Codes of Ethics and Professional Standards}

The professional standards used in developing software attempt to reflect wider community expectations. The wider community within which developers operate needs to have confidence in the IS profession, that they will do their job in an ethical manner taking into consideration the community's interests, and that they possess relevant skills and qualifications. If the community were to lose faith in the IS profession, government may feel compelled to step in and legislate. It might be argued that it is not in the IS profession's best interests that the government might so legislate, so restricting their practice, their flexibility, and in consequence increase costs due to expenses incurred by compliance. It may be argued that the IS development industry needs to show that it is capable of self-regulation. In response, a number of professional associations have developed codes of ethics and codes of professional conduct (Anderson et al. 1993).

The IS industry by its nature is multi-disciplinary and therefore attracts employees from a wide range of backgrounds. Due to the dramatic growth in IS many people have gained employment within the IS industry and have become, by definition, "IS professionals". A number of these people have not undertaken formal study in the IS discipline, and many have not been formally exposed to the ethical considerations of professional practice. Moreover, there is a significant difference between being made aware of the ethical issues and becoming a responsible ethical professional (Martin and Welt 1999). Gotterbarn (1999) suggests that members of the computing profession have to take a stand to ensure it is clear that it is no longer acceptable to do inferior work or to do work that damages the computing profession's basic values. The IEEE$\mathrm{CS}$ and the ACM have identified that software engineering should be classified as a profession. As a profession, members are expected to act ethically and competently, and the professional society is expected to support their ethical behaviour and to hold them accountable when they deviate from endorsed codes and behaviours (Rosenberg 1998).

If ethics are to be part of IS development then Wood-Harper et al. (1999) prescribes two principles to which one should adhere:

- Principle 1 - ethical reasoning should be conducted throughout the life of an information system, including inception, testing, distribution, modification and termination.

- Principle 2 - the design of every IS should include the design of its ethical use, the design of its ethical distribution, the design of its ethical risk, and the methods of justifying ethical criteria.

Ethics are behavioural guidelines that parallel certain legal standards. Ethical standards have long existed in the computer field and have been incorporated in various agreements and contracts for many years (Ulrich 2000). Ulrich suggests that by incorporating ethical standards into IS contracts, corporations, vendors and individuals have specific guidelines that can be cited in a court of law should a dispute arise.

\section{Quality Standards}

Quality standards involved in an IS development contract include not only the professional practice standards that should be followed, but also include the standards that should be followed when developing the product. To prove that a contract has been met, the software needs to be developed not only to the specifications but also to an expected level of quality. It can be argued that if an expected level of quality is to be achieved, one should require a developer to have some kind of quality management process in place.

Quality standards serve two purposes: they provide guidance to organizations installing quality process systems; and they are the basis for the certification of quality systems (Van Der Pijl et al. 1997). The guidance that the quality standards provide seeks to help the IS profession to meet the quality expectations that are required within a contract. The certification that can be obtained provides reassurance and recognition to the 
wider community. Three prominent software quality process widely recognised by the IS profession are: ISO 9000 series accreditation, the Capability Maturity Model (CMM) and SPICE (see SPICE 1999).

There is no clear consensus on the relative value of these three quality process standard assessment mechanisms. Indeed, the more organisations use quality standards the more it is possible that parties participating in software contracts will use different quality standards (Van Der Pijl et al. 1997). Further, one might expect that standards will keep being developed to meet different needs. The problem with this is that the public will not know which standard should be used and confusion may well further grow. Such confusion may well surface in the courts.

\section{IS Development Contracts}

An IS development contract is designed as a legal instrument that the client and vendor sign to assent to the development of a product and/or service. Central to the contract are the terms and conditions it contains. These terms and conditions address who is to develop the product and/or service and the solution that is to be provided. The terms and conditions within the contract have implications for the general public, the IS industry and the legal profession. The public wants to ensure that the system developed will not do them harm. The IS profession wants to ensure that the software product is developed in accordance with the terms in the IS development contract. The legal practitioners are involved with the IS development contract either at the beginning, with the negotiation and drawing of the contract, or if it comes into dispute and the parties seek legal redress. To try to prevent the contract from coming into dispute IS professionals need to understand the processes to be followed before entering into a contract, what is required in a contract, and how to manage that contract.

\section{Processes before entering into an IS Contract}

The first part of the contract process is to determine the type of relationship that is required. Nam et al. (1996) outline four main types of relationships: support; reliance; alignment and alliance. The type of relationship that is decided upon determines the expressed terms that are needed to be included in the contract. Once the type of relationship is decided the next step is to choose a contractual partner. Binstock (1999) identifies that in choosing a partner it is important to make sure that they have software development certification (e.g., ISO 9000 or at least CMM Level 2 or 3). The contract should also contain provision for termination at short notice if the wrong party has been selected and their performance is not satisfactory (Bramson 1990). This is to ensure that if the wrong partner has been selected then the contract can be terminated before either party suffers significant loss (Frost 1999).

\section{Contents of an IS Development Contract}

In the development of the contract it is important the contract contains detailed specifications and schedules (Binstock 1999, Frost 1999). Detailed specifications are important, especially in an industry where clarity is, some would argue, a scarce commodity. Hollington (2000) identifies two significant problems with specifications:

- Gaining an understanding of what is wanted; and

- Articulating what you want so that others can understand it.

Dakin (1996) points out that the process of drawing up a written contract is intended to assist in this understanding. However, when negotiating something as technical as IS development there is room for error. The first step in designing a good contract is to ascertain the true objectives of each party. Bragg and Allen (2000) identify a number of terms that should be addressed, including: defining intellectual property rights; establishing pricing; defining the customer's responsibility; identifying deliverables; defining acceptance criteria / procedures; providing limited indemnity; and defining an exit strategy / dispute resolution process.

In association with a contract a requirements document needs to be prepared. This document has the greatest potential impact on litigation avoidance, as it is a source of a statement of the functions the software is to deliver. Bragg and Allen (2000) and Binstock (1999) point out that clarity of communication is essential to a well developed IS development contract. Lawrence (2000) supports the need to communicate, but goes further to indicate that communication in IS development projects needs to outline the value of the project; what problem is being solved; product design and plans; project status; and product status. Welch (1999) identifies that, as part of building the contractual relationship, it is important that there is a transfer of knowledge to the client. Confusion or ambiguity in any of these areas can be fatal to a project (Lawrence 2000). 


\section{Contract Management}

Contract management is clearly different to project management. IS professionals often get contract management and project management confused. Project management can be defined as the systematic approach of analysing, organising and completing a project (Norris et al. 1996). Contract management involves looking at and reviewing the contractual document (Dakin 1996). Davis (1995) states that good management is more important than good technology. It is considered by some to be good management to organise the contract into small jobs and then sign each off before moving on to the next one (Bramson 1990). This notionally ensures that both parties to the contract are aware of the present stage of a development, and whether the contract is being met.

Mah and Stone (2000) discuss four early warning signs of IS development contract breakdown. The first is identified as 'a shot gun wedding' where contracts are entered into quickly as the parties believe they will fix the contract later. The second is a poor or inadequate metrics framework - often contracts do not contain metrics. These metrics are vital for project estimation, service level determination and productivity benchmarking (Dakin 1996). The third is treating outsourcing as a transaction. A theme in soured contracts is that the relationship failed. Relationship management is an area where parties experience a breakdown. Outsourcing deals are business transactions but are also relationships. The final warning sign lies in contractual dispute resolution clauses. When you see dispute resolution clauses you often don't see processes for managing conflicts - what you find are ways to escalate them.

All of the previous discussion looked at how to stop things from going wrong and where they go wrong. Lawrence (2000) discusses why they go wrong. Specifically, Lawrence suggests that the parties:

- Start out unprepared;

- Underestimate the complexity involved;

- Choose the wrong design strategy; and

- Leave the requirements vague enough that any interpretation would be plausible.

\section{LEGAL PRACTITIONERS AND IS CONTRACTS}

We turn now from a consideration of professional behaviour, quality and quality processes, and the IS contract itself, to the law that underpins the drafting and interpretation of software development contracts. The laws discussed in this section relate to the Laws of the Commonwealth of Australia.

Contract law is predominantly based upon law that has been established by judges in appellate cases. This is the way common law develops. Legislation increasingly plays a role in augmenting or changing common law. An IS development contract is a contract in the full legal sense of the word and may therefore be reviewed by a judge in the event of dispute. When disputes arise it is usually as a result of a perceived breach of the contract. For this reason this brief review of relevant literature focuses on disputes which involve breaches of contract.

\section{Establishing a contract}

In judgement of a dispute, the court, when looking at a contract, will establish whether or not a contract has been formed. To form a contract there must be an offer, acceptance, consideration and an intention to create legal relations. These four elements must be established to prove that there was an IS development contract in place. If a contract exists then it will be necessary to assess what is in the agreement. The terms of the agreement may be express or implied.

\section{Express terms of an IS contract}

Generally, contracts of the kind being discussed in this paper will include express terms; express terms are the terms that are specifically stated within the contract, either orally or in writing. Identification of express terms is simply a matter of examining the contractual document (if the contract is in writing, which is the case for most IS development contracts).

In the course of negotiations, parties will often refer to various matters that pertain to their particular situation. Some statements made during the negotiation may be intended to be a term of the contract while other matters or points may not be considered as important. A term is a contractual statement which amounts to an undertaking or guarantee by the maker of the statement, that it is true or that the maker had reasonable grounds for making it. Importantly, the terms must be delineated and expressed. Difficulties arise when the parties have differing views, or representation, of what forms the basis (or terms) of the IS contract. A representation that does not accord with the true facts (past or present) may render a contract voidable. This representation may include statements of fact, advice, or opinion made in negotiation, which are inaccurate or misleading. At this 
point it is important to distinguish a term from a representation, insofar as contract law is concerned. If a representation is untrue then the only common law remedy is rescission (though there are no extensive statutory remedies under the Trade Practices Act 1974 (Cth) (TPA) and Fair Trading Acts (of the various states)).

If a pre-contractual statement becomes a term then the remedy of damages will be available, and depending on the seriousness of the breach, the possibility of terminating the contract. Therefore, it is important to establish whether a statement made during negotiations is a term that was agreed upon by both parties.

Within an IS development contract there are a number of express terms that should be included. They include terms which deal with: supply and distribution; research and development; options and rights of first refusal; joint venture relationships; system integration; licence; specifications; installation and tests; price and payment; records and other administration; warranties; maintenance; support and spare parts; suspension; termination; after termination; subcontracting; relationship; assignment; severance; and waiver terms (Calvert 1995).

\section{Implied terms of an IS contract}

Implied terms are part of a contract, even though they are not stated, and merely reading the document will not expose them. There are two types of implied terms: implied by fact; and implied by law. As stated in Secured Income Real Estate (Australia) Ltd v St Martins Investments Pty Ltd ${ }^{1}$, there are five requirements to be satisfied before a term can be implied by fact. Specifically the term should:

- Not contradict any express term of the contract;

- Be reasonable and equitable;

- Be necessary to give business efficacy to the contract — that is no term will be implied if the contract is effective without it;

- So obvious it goes with saying; and

- Be capable of being clearly expressed.

These requirements ensure that implied terms are reasonable and will not interfere with the contract. The significant point behind this is that terms will be implied when they are necessary to make the contract work in the way the parties intended. The more extensive the negotiations and the more detailed the resulting contract, the less likely it is that a term will be implied because it will be difficult to convince the court that a necessary term was left out (Codelfa Construction Pty Ltd v State Rail Authority of NSW ${ }^{2}$ ).

A term may be implied at common law, in order to express a generally accepted incident of the contract, or to complete an incomplete contract (Carter 1994). In these types of situations the terms are incidents of the contracts because judicial decisions have indicated that it is to be expected of the parties. Where there is not such a situation, due to unique facts, then a term may be implied as a matter of justice and fairness (Carter 1994). A term may also be implied by statute. Those with the greatest relevance are Consumer Protection Legislation and Sale of Goods Legislation.

Consumer Protection Legislation, such as the Trade Practices Act (TPA), can imply terms. A representative case is Caslec Industries Pty Ltd v Windhover Data Systems Pty Ltd ${ }^{3}$. In this case a computer installation was in dispute. The main thrust of the case is that after the software was installed expectations were not met as to what the system was to do. Hence there was a disagreement as to the terms of the software agreement. The court found that not only was there a breach of the contractual terms but also the implied terms, warranty and being reasonably fit for purpose under s 69(1) of the TPA.

The consumer protection provisions of the TPA that are the most relevant for technology suppliers and consumers are (Calvert 1995):

- Implied terms into contracts;

- Imposed liability on manufacturers directly to consumers for goods of unmerchantable quality (for where goods are not purchased directly from the manufacturer); and

- Imposed certain minimum standards of conduct (prohibiting misleading and deceptive conduct).

For the TPA to be implied into a contract there must be a consumer. Section 4B of the TPA defines a consumer as a person who shall be taken to have acquired particular goods as a consumer if the price of the goods did not exceed $\$ 40,000$ :

- Where the goods exceeded $\$ 40,000$, the goods were of a kind ordinarily acquired for personal, domestic or household use; and

\footnotetext{
1 (1979) 144 CLR 596 at 605-6

2 (1982) 149 CLR 337

${ }^{3}$ (Federal Court of Australia, Gummow J, no G627/90, 13 August 1992, unreported)
} 
- Were not acquired for the purpose of re-supply or for the purpose of using them up or transforming them.

Unfortunately the $\$ 40,000$ limit is very difficult to apply, as it is not clear what is involved in calculating the price. It might involve the sale of 20,000 of the same item at $\$ 10.00$ each (hence total contract price is $\$ 200,000$ but it is likely to be a sale of goods to a consumer because the unit price is below $\$ 40,000$ ). However in the case of maintenance, where the contract might specify it to be $10 \%$ of the system price of $\$ 1,000,000$, it is more problematic. If the fees are paid monthly then it is less than $\$ 40,000$ each month. Where do you draw the line?

The TPA defines goods and services very broadly. Most IS development contracts will come under one or the other. However sometimes it is very hard to categorise technology. While it is clear that a computer system, hardware and software provided together can be goods, it is not clear whether goods includes software supplied separately (Toby Constructions Products Pty Ltd v Computa Bar (Sales) Pty Ltd ${ }^{4}$ ). Categorisation of goods and services is important, as the conditions and warranties implied for each category are different. The terms implied for goods are more comprehensive. This remains unclear as the courts have not come to a definite answer themselves as in Caslec Industries Pty Ltd v Windhover Data Systems Pty $\operatorname{Ltd}^{5}$ where the court considered software to be services, whereas in St Albans City Council v ICL ${ }^{6}$ the court considered software to be goods.

The requirement of the consistency between the implied and expressed terms of the contract applies to all types of implied terms, as has been seen in Secured Income Real Estate (Australia) Ltd v St Martins Investments Pty $\mathrm{Ltd}^{7}$, where one of the requirements to give business efficiency is that it does not contradict express terms. A term implied by law will also not be implied if it was found to be inconsistent with the express terms. Therefore it is not easy to imply a term into an IS development contract. The term, if it is to be implied, must serve a significant purpose.

\section{RESEARCH POPULATION: IS PROFESSIONALS AND LEGAL PRACTITIONER COHORT}

An IS development contract negotiation involves two key stakeholder groups: IS professionals; and legal practitioners. For the purpose of this exploratory research, representatives of both groups were identified in the Melbourne and Geelong areas of Australia. A total of 10 professionals were approached (4 legal practitioners and 6 IS professionals). The IS professionals selected were all members of middle to senior management in their organisations, working within the Information Technology industry. The legal practitioners held senior positions within their firms, specialising, or having a significant interest and experience in, Information Technology contracting practice. Participants in the interview program were selected initially for an interview, based upon their position titles, with particular interest in positions related to the negotiation, preparation and/or oversight of IS development contracts.

The principle question to be addressed in the present research program is:

Are there differences in the perceptions held by legal practitioners and IS professionals of IS development contracts?

To proceed, this question was decomposed into four sub-questions:

- What is the accepted legal opinion of how contract law applies to IS development contracts?

- What are the perceptions that IS professionals hold of IS development contracts?

- What are the perceptions that legal practitioners hold of IS development contracts? and

- Are there differences between the perceptions held by the IS professionals and the legal practitioners?

The first of these questions has been addressed, in part, in the preceding section 3 of this paper and is canvassed further below. Findings to date related to the remaining three questions, drawn from the program of semi-structured interviews, are also reported.

\section{RESEARCH FINDINGS - DIFFERENCE IN PERCEPTIONS}

The aim of this research was to conduct an exploratory study of the differences in perceptions of IS development contracts held by the key stakeholder groups (IS professionals and legal practitioners). The semistructured interview covered a number of key issues, with perceptions been uncovered spanning matters such

\footnotetext{
4 (1983) 2 NSWLR 48

${ }^{5}$ (Federal Court of Australia, Gummow J, no G627/90, 13 August 1992, unreported)

${ }^{6}$ (1994, unreported)

${ }^{7}$ (1979) 144 CLR 596 at 605-6
} 
as: pre-contractual processes; contents of a contract; contract management; aspects of IS professional practice; expectations of quality; the specification of a quality process; contract management; common legal advise; awareness of case law and major problems and issues of IS contracts (Hodges 2000).

This section has been structured in terms of the four sub-questions, as outlined above with tentative conclusions being drawn against each of these sub-questions.

\section{What is accepted legal opinion on the application of contract law to IS development contracts?}

Contract law provides a number underlying principles that are used as guidance in the development of an IS contract.

\section{An IS contract as a legal instrument}

A contract is a legally binding document that contains terms and conditions that state the obligations of the parties to that contract. If these obligations are not met then a breach of contract has occurred. The injured party may seek legal advice that may lead to the process of mediation, arbitration, or litigation and therefore obtainment of an appropriate remedy. Therefore to form a legally binding contract the contract must consist of four elements: offer; acceptance; consideration; and the intention to create legal relations.

\section{Express and implied terms of an IS contract}

A contract has both express and implied terms. Both must be met to fulfil the obligations of the contract. The express terms explicitly state the obligations of the parties to the contract and are clearly delineated. These include the requirement specification, intellectual property rights, pricing and acceptance criteria. In contrast, the implied terms are not defined within the contract. Instead, they can either be implied by fact or by law. Therefore, implied terms are not only hard for the courts to establish, but also for the legal and IS profession to define. Often community, industry and government expectations establish the implied terms of a contract. These can include professional practice and quality.

\section{What are the perceptions that IS professionals hold of IS development contracts?}

A number of perceptions have been uncovered from interviews with the IS professionals' cohort, spanning matters such as: entering into a contract (e.g., pre-contractual processes, contract management); aspects of IS professional practice; expectations of software quality specification and quality management; common legal advice; and awareness of case law.

\section{Entering into a Contract}

Entering into a contract can be seen as a two-step process, involving the organisation (pre-contractual processes) and the drafting of the contract. It was perceived that the pre-contractual processes should include: requirements specification; obtaining a quotation of tender; vendor investigation; and negotiation. The IS practitioners, however, believed that the processes they themselves identified were not universally followed. Pre-contractual processes can form the basis of the main terms of the IS development contract. IS professionals perceive that the contract should include: pricing; requirement specification; intellectual property rights; and acceptance criteria. Entering into the contract is not the last stage - the contract also needs to be managed. To emphasise this, one IS professional stated that: "Its critical. You need to have a framework that facilitates openness so that you can exchange information quickly because it doesn't take long for a project to get off the rails".

\section{IS Professional Membership}

Membership of a professional association was not seen as an important component of an IS development contract by the IS professionals. However the IS professionals reported that adherence to a code of ethics as well as a code of conduct should be specifically incorporated in an IS development contract. A possible interpretation of this is that IS professionals tend not to rank membership of a professional association as essential, or indeed maybe they consider it irrelevant, to the day-to-day conduct of IS development activities. 


\section{Software Quality Management Systems}

There was a perception that an expectation of quality should be expressed within an IS development contract. There was, however, a diversity of perceptions of what the requirements of the quality process should be. It was encouraging, however, that the IS professionals were able to name some key quality expectations and processes that could be followed in the execution of an IS development project (e.g., the ISO 9000 series and CMM).

\section{Legal Advice to the IS Professional}

Legal advice is usually given in relation to interpretation, although IS developers tend to avoid seeking legal advice. This was supported with the following statement from an IS professional: "We try to avoid that like the plague". Indeed one IS professional clearly stated "It's a big point as to the value seeking legal advice brings - they tend to introduce as many new difficulties as they can."

\section{IS Professional Legal Knowledge}

Four of the six IS professionals claimed to be aware of relevant case law. Their awareness, however, appeared to be based only on IS cases reported in the popular press (e.g., cases involving IBM, Microsoft, and Apple) often cases which actually had little to do with testing the application of contract law.

\section{What are the perceptions that legal practitioners hold of IS development contracts?}

A number of perceptions have been uncovered from the interviewed legal practitioners, spanning matters such as: entering into a contract; main terms of an IS contract; contract management project management; aspects of IS professional practice; and IS professional membership.

\section{Entering into a Contract}

The legal practitioners perceive that pre-contractual processes should include: requirement specification; and vendor investigation. However, the legal practitioners believed that these processes were not universally followed within the IS industry.

\section{Main terms of a IS Contract}

The main terms in an IS development contract were identified as: requirement specification; and intellectual property rights.

\section{Contract management and project management}

Although the IS profession enter into contracts, legal practitioners did not believe that the contracts were managed after signing. One of the legal practitioners made the statement that: "Almost by definition they come to us too late, and they really do have a very big problem by the time they come to us." Further, the major problem and issue associated with IS development contracts raised by legal practitioners was requirement specification.

\section{Incorporation of IS Professional membership into an IS contract}

There was diverse opinion as to the significance of incorporating association membership in an IS development contract. Legal practitioners certainly acknowledged that there should be adherence to a code of ethics, but they did not believe that a code of conduct should be specifically incorporated in an IS development contract.

\section{Are there differences between the perceptions held by the IS professionals and the legal practitioners} when examining IS contracts?

Central to this work has been the comparison of the two cohorts and their responses. The main differences between the two cohorts covered: pre-contractual process; main terms of the IS contract; contract and project management; professional membership; code of conduct and ethics in an IS contract; and software quality management. 


\section{Pre-contractual Process}

With regard to the pre-contractual processes, IS professionals perceived the quotation of tender and negotiation as important. In contrast, the cohort of legal practitioners did not rate this as highly. Both cohorts said that the pre-contractual processes they identified as important were not universally followed.

\section{Main terms of an IS contract}

The IS professionals identified the establishment of pricing and acceptance criteria as the main terms of an IS development contract while the cohort of legal practitioners did not rate these as highly.

\section{Contract management and project management}

A significant difference was in the perception of contract management. The IS professionals believed contract management was routinely carried out, whilst the legal practitioners believe it was rarely practiced by IS professionals. This may be attributable to IS professionals identifying project management, which presumably they do routinely carry out, with contract management. These are viewed, one might argue quite correctly, by the legal profession as distinctly different activities.

\section{Incorporation of IS Professional membership in an IS contract}

There was a diverse response to questions concerning the incorporation of professional association membership in to an IS development contract from the legal practitioners. The IS professionals believed that it was of no contractural significance. An interpretation is that IS professionals tend not to rank membership of a professional association as essential, or indeed maybe consider it irrelevant, to the day-to-day conduct of IS development activities.

\section{Code of conduct and professional ethics in an IS contract}

There was also a difference in perceptions in relation to adherence to a code of conduct being incorporated in an IS development contract. IS professionals supported its inclusion, while the legal practitioners were against the notion.

\section{Software quality management}

The requirement of specifying quality processes in an IS development contract received a diverse response from the IS professionals, while the legal practitioners supported the idea. This may suggest that the IS profession is somewhat ambivalent to the whole notion of quality software development processes. The IS professionals were, however, able to name several quality processes that might be used, while the legal practitioners found it difficult to specify any.

\section{CONCLUSION}

Although this is a limited exploratory study, there is tentative evidence of a number of fundamental differences in the perceptions of IS development contracts held by IS professionals and legal practitioners, as highlighted in this paper. Further research, with more substantial cohort sizes, is recommended to confirm and further delineate these differences.

\section{REFERENCES}

Anderson, R. E., D. G. Johnson, et al. (1993). "Using the new ACM code of ethics in decision making." Communications of the ACM 36(2): 98 - 102.

Binstock, A. (1999). “Outside Development Partners.” Informationweek (757): 133-140.

Bragg, T. and R. Allen (2000). "Litigation Avoidance: A Lifecycle Approach.” Cutter IT Journal 13(9): 411.

Bramson, R. S. (1990). “The Dotted Line.” Information Strategy: The Executive's Journal 7(1): 44-47.

Calvert, M. (1995). Technology Contracts. Melbourne, Reed International Books Australia Pty Limited trading as Butterworths.

Carter, J. W. (1994). Outline of Contract Law in Australia. Melbourne, Reed International Books Australia Pty Limited trading as Butterworths.

Dakin, K. (1996). “Keys to Engineering a Workable Contract.” IEEE Software(January): 99-100. 
Davis, A. M. (1995). 201 Principles of Software Development. Sydney, McGraw-Hill, Inc.

Frost, L. I. (1999). "You Get What You Ask For." The Journal of Business Strategy 20(3): 11-14.

Gotterbarn, D. (1999). "Specifying the standard - Make it right." Computers and Society (September): 13-16.

Hodges, K. (2000). "An Exploratory Investigation of Stakeholder Perceptions of Information Systems Development Contracts," Honours Thesis, School of Management Information Systems, Deakin University.

Hollington, P. (2000). "You Don't Always Get What You Want: But, You do Usually get What you Ask For!" Cutter IT Journal 13(9): 26-30.

Lawrence, B. (2000). "Learnings of an Expert Witness.” Cutter IT Journal 13(9): 31-35.

Mah, M. and D. Stone (2000). "IT Relationship Management: Four Early Warning Signs of Breakdown." Cutter IT Journal 13(9): 12-19.

Martin, C. D. and E. Yale Welt (1999). "From Awareness to Action : Integrating Ethics and Social Responsibility into the Computer Science Curriculum." Computers and Society (June): 6-14.

Nam, K., S. Rajagopalan, et al. (1996). "A Two Level Investigation of Information Systems Outsourcing." Communications of the ACM 39(7): 36-44.

Norris, M., P. Rigby, et al. (1996). The Healthy Software Project: A guide to successful development and management. Chichester, John Wiley \& Sons.

Rosenberg, R. S. (1998). "Beyond the Code of Ethics : The Responsibility of Professionals Societies." Computers and Society ACM Policy '98: 18-25.

SPICE (1999). “An Introduction to the Documents." Last Accessed: 10 $0^{\text {th }}$ May 2000. http://www.sqi.gu.edu.au/spice/suite/intro.html

Ulrich, W. (2000). "IT Ethics: Heading off Legal Challenges by Doing the Right Thing." Cutter IT Journal 13(9): 20-25.

Van Der Pijl, G. J., G. J. P. Swinkels, et al. (1997). "ISO 9000 versus CMM: Standardisation and certification of IS development." Information and Management 32: 267-274.

Welch, A. (1999). "Communication Plays Vital Role in Outsourcing Partnerships.” Computer Dealer News 15(36): 31-32.

Wood-Harper, A. T., S. Corder, et al. (1999). "Ethically Situated Information Systems Development." The Australian Computer Journal 31(3): 66-71.

Yourdon, E. (2000). "Introduction" Cutter IT Journal 13(9): 2-3 